\title{
A national dose analysis of guided tumor destruction: influence of sex, age, localization and destruction technique used
}

\author{
Matthieu Rojo ${ }^{1}$, Aymeric Hamard ${ }^{1}$, Chris Serrand ${ }^{2}$, Hélène de Forges ${ }^{1}$, Jean-Paul Beregi ${ }^{1}$, Joël Greffier ${ }^{1}$, \\ Julien Frandon ${ }^{1}$ \\ ${ }^{1}$ Department of Medical Imaging, Nîmes University Hospital, University of Montpellier, IMAGINE Team, Nîmes, France; ${ }^{2}$ Department \\ of Biostatistics, Clinical Epidemiology, Public Health and Innovation in Methodology (BESPIM), Nîmes University Hospital, University of \\ Montpellier, Nîmes, France \\ Contributions: (I) Conception and design: JP Beregi, J Greffier, J Frandon; (II) Administrative support: J Greffier, JP Beregi; (III) Provision of study \\ materials or patients: M Rojo, A Hamard, J Greffier, J Frandon; (IV) Collection and assembly of data: M Rojo, A Hamard, J Greffier, J Frandon; (V) \\ Data analysis and interpretation: M Rojo, C Serrand, H de Forges, J Greffier, J Frandon; (VI) Manuscript writing: All authors; (VII) Final approval of \\ manuscript: All authors.
}

Correspondence to: Julien Frandon. Department of Medical Imaging, Nîmes University Hospital, Nîmes, France. Email: julien.frandon@chu-nimes.fr.

Background: Percutaneous destructions of tumor lesions by ablation (microwave, radiofrequency or cryoablation) under computed tomography (CT) guidance allow high efficiency with minimally-invasive techniques, and acute needle placement and follow-up during procedure. This study investigated the impact of patient and technique parameters on the dose delivered during these procedures under CT guidance.

Methods: Data were extracted from a previous nationwide retrospective study. Patients who underwent percutaneous destruction of bone lesions, abdominal and lung tumors were included. Univariate and multivariate linear regression of the dose length product (DLP) log were performed, according to patient's gender, age, lesion location, destruction technique, adjusted to the participating center.

Results: A total of 822 patients (556 men), of mean age $62 \pm 14$ years, were included: 150 patients had bone lesions, 463 abdominal and 209 thoracic tumors. The mean DLP was $991.6 \pm 979.0 \mathrm{mGy} \cdot \mathrm{cm}$ for patients with bone lesions, $2,130.7 \pm 2,051.8 \mathrm{mGy} \cdot \mathrm{cm}$ for abdominal tumors and $825.2 \pm 545.4 \mathrm{mGy} \cdot \mathrm{cm}$ for lung tumors. In multivariate analysis, the age was significantly associated with higher DLP for bone $(\mathrm{P}=0.0082)$ but not for abdominal and thoracic lesions; the DLP was significantly higher in men for abdominal tumors $(\mathrm{P}<0.0001)$ while sex had no impact on the dose for bone and thoracic lesions. The dose depended on the lesion location only for bone $(\mathrm{P}<0.0001)$ percutaneous destructions. The technique was not correlated to DLP for all lesions.

Conclusions: Patient and tumor characteristics such as sex, age and lesion location impacted on the dose delivered during percutaneous destructions of bone, abdominal and thoracic lesions, but not the destruction technique used. Further studies are needed to propose sharper reference dose levels.

Keywords: Physics; radiology, interventional; radiation exposure; multidetector computed tomography; percutaneous destruction

Submitted Jul 20, 2021. Accepted for publication Nov 29, 2021; Published online: 04 Jan 2022.

doi: 10.21037/qims-21-744

View this article at: https://dx.doi.org/10.21037/qims-21-744 


\section{Introduction}

The number of percutaneous destruction procedures has greatly increased these last 25 years, with more and more arguments in favor of their interest and effectiveness (1). Percutaneous tumor destruction plays a key role in the management of benign and malignant tumors (2-5). These ablation techniques, mainly radiofrequency ablation (RFA), microwave ablation (MWA) and cryoablation, allow treatment of high efficiency and are often associated with less comorbidities than conventional surgery (6). In addition, imaging guidance offers the possibility to achieve minimally invasive approaches, allowing acute needle placement, and follow-up during the whole procedure. Ultrasound guidance is usually sufficient for superficial lesions, but deeper or complex procedures often require CT guidance. Its field has therefore been widened these last years, mainly used for liver, kidney, lung and bone lesions (2-5). However, while CT guidance demonstrates many advantages, dose delivered during these procedures is consequent (7-9). Especially, among most commonly performed categories of CT guided procedures, which include procedures for pain (infiltration, vertebroplasty, and screw fixation), oncology (percutaneous biopsy or percutaneous tumor destruction), or infection (drainage), percutaneous destruction appears to deliver the highest doses to the patient (7).

As CT-guided percutaneous destructions are now performed more often, especially with curative intent (6), efficiency of these procedures induces longer life expectancy with the drawback of these high doses: this could expose to a risk of secondary radiation-induced cancer (10).

In this study, based on a previous nation-wide study (7), we investigated parameters that may be associated with an increased delivered dose during CT-guided percutaneous destructions procedures.

We present the following article in accordance with the STROBE reporting checklist (available at https://dx.doi. org/10.21037/qims-21-744).

\section{Methods}

\section{Study design and patients}

The study was conducted in accordance with the Declaration of Helsinki (as revised in 2013). The study was approved by the Institutional Review Board of Nîmes University Hospital (No. 19.01.03) and informed consent for this retrospective analysis was waived. The present study was based on a previous multicenter nation- wide retrospective study conducted in 2019 by our team to propose the national reference levels of main interventional procedures under CT guidance (7). Here we performed extraction of data from patients who underwent percutaneous destruction of bone lesions, abdominal tumors or lung tumors between the $8^{\text {th }}$ August, 2017 and the $31^{\text {st }}$ July, 2019. Patients who underwent percutaneous alcohol destruction were excluded from the analysis.

\section{Data extracted}

For all patients, gender, age, anatomical location of the lesion, ablation technique used (RFA or MWA, cryotherapy or laser) and total dose length product (DLP) were extracted from the data of the previous study. The patients were divided into 3 subgroups according to the general location of the lesion (bone, thorax, abdomen-pelvis). Patients with bone lesions were classified in 8 categories: 4 for the lesions of the axial skeleton [spine (cervical and/ or thoracic and/or lumbar); shoulder girdle, pelvis and ribs] and 4 for lesions of the appendicular skeleton (hand, upper limb except hand, foot, lower limber except foot). Patients with abdominal tumors were divided in 3 categories: liver tumors, kidney tumors and other abdominal locations (including adrenal, colon, retroperitoneum, peritoneum, abdominal wall and psoas). Thoracic lesions were grouped in the lung category.

\section{Statistical analysis}

We analyzed the impact of the patient's gender or age, the anatomical location of the lesion and the technique used on the total DLP in percutaneous destructions under CT guidance.

Statistical analysis was performed using SAS 9.4 ${ }^{\circledR}(2017$, SAS Institute Inc., Cary, NC, USA) software. Because the DLP variable did not show a Gaussian distribution, a logarithmic transformation was used for analysis. Univariate and multivariate linear regressions of the DLP Log were performed, according to gender, age, anatomical location of the lesion, destruction technique used and number of helical acquisitions with adjustment to the inclusion center. For each population subgroup, the age variable was divided into three classes (thirds). A P value of the regression model was attached to the corresponding $\log$ (DLP). Significance was set at $\mathrm{P}<0.05$. DLP estimated means, with their $95 \%$ confidence interval (95\% CI) are presented after reverse transformation of the $\log$ DLP 


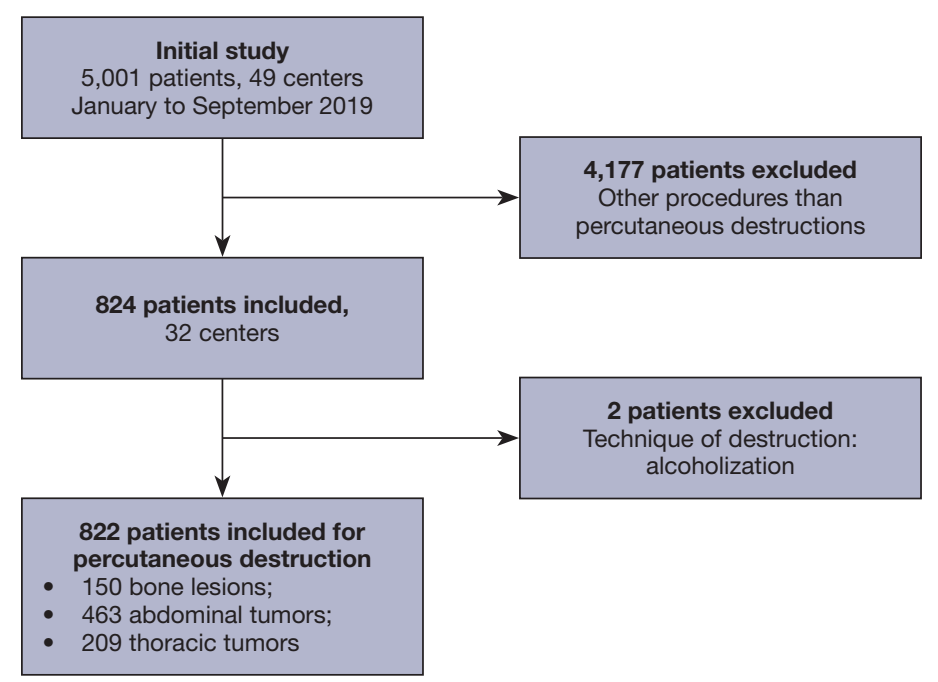

Figure 1 Flowchart of the study.

Table 1 Distribution of dose length product values

\begin{tabular}{lcccccccc}
\hline \multirow{2}{*}{ Percutaneous destruction of } & \multirow{N}{*}{} & \multicolumn{5}{c}{ Dose length product (mGy·cm) } \\
\cline { 3 - 8 } & & Minimum & Q1 & Median & Q3 & Maximum & Average & SD \\
\hline Bone lesions & 150 & 52 & 339.0 & 637.1 & $1,316.3$ & $6,142.0$ & 991.6 & 979.0 \\
Abdominal tumors & 463 & 112 & $1,012.8$ & $1,545.4$ & $2,479.0$ & $16,455.0$ & $2,130.7$ & $2,051.8$ \\
Thoracic tumors & 209 & 75 & 437.0 & 687.7 & $1,112.2$ & $3,157.1$ & 825.2 & 545.4 \\
\hline
\end{tabular}

Q1, first quartile; Q3, third quartile; N, number of patients; SD, standard deviation.

estimates.

\section{Results}

\section{Patients}

From the 5,001 patients of 49 centers of the previous study, 824 (in 32 centers) underwent tumor percutaneous destruction (Figure 1). Two patients were excluded because destruction was performed by alcoholization. A total of 822 patients, 266 women and 556 men, were included in the study, of mean age $62 \pm 14$ years old. Among them, 150 had bone lesions ( 62 women, 88 men, mean age $40 \pm 18$ years, 9 centers), 463 abdominal tumors ( 120 women, 343 men, mean age $67 \pm 12$ years, 25 centers) and 209 had thoracic tumors ( 84 women and 125 men, mean age $66 \pm 12$ years, 11 centers). Overall, 699 patients $(85.0 \%)$ were treated for one lesion, 91 patients $(11.1 \%)$ treated for 2 lesions and 32 patients (3.9\%) treated for 3 or more lesions.

\section{Dose}

The mean total DLP was $991.6 \pm 979.0 \mathrm{mGy} \cdot \mathrm{cm}$ for patients with bone lesions, 2,130.7 $\pm 2,051.8 \mathrm{mGy} \cdot \mathrm{cm}$ for patients with abdominal tumors and $825.2 \pm 545.4 \mathrm{mGy} \cdot \mathrm{cm}$ for patients with lung tumors (Table 1). The mean total DLP for patients with one lesion treated was $1,509 \pm 1,619 \mathrm{mGy} \cdot \mathrm{cm}$, it was $2,103 \pm 2,280 \mathrm{mGy} \cdot \mathrm{cm}$ for patients with two lesions and $1,899 \pm 2,034 \mathrm{mGy} \cdot \mathrm{cm}$ for patients treated for 3 or more lesions (Table S1). The total DLPs obtained in univariate analysis according to gender, age and technique used are presented in Figure 2 for patients with bone lesions, and in Figures 3,4 for patients with abdominal and thoracic tumors, respectively.

\section{Multivariate analyses}

The multivariate analysis of the total DLP adjusted on gender, age, lesion location, technique used and number of 

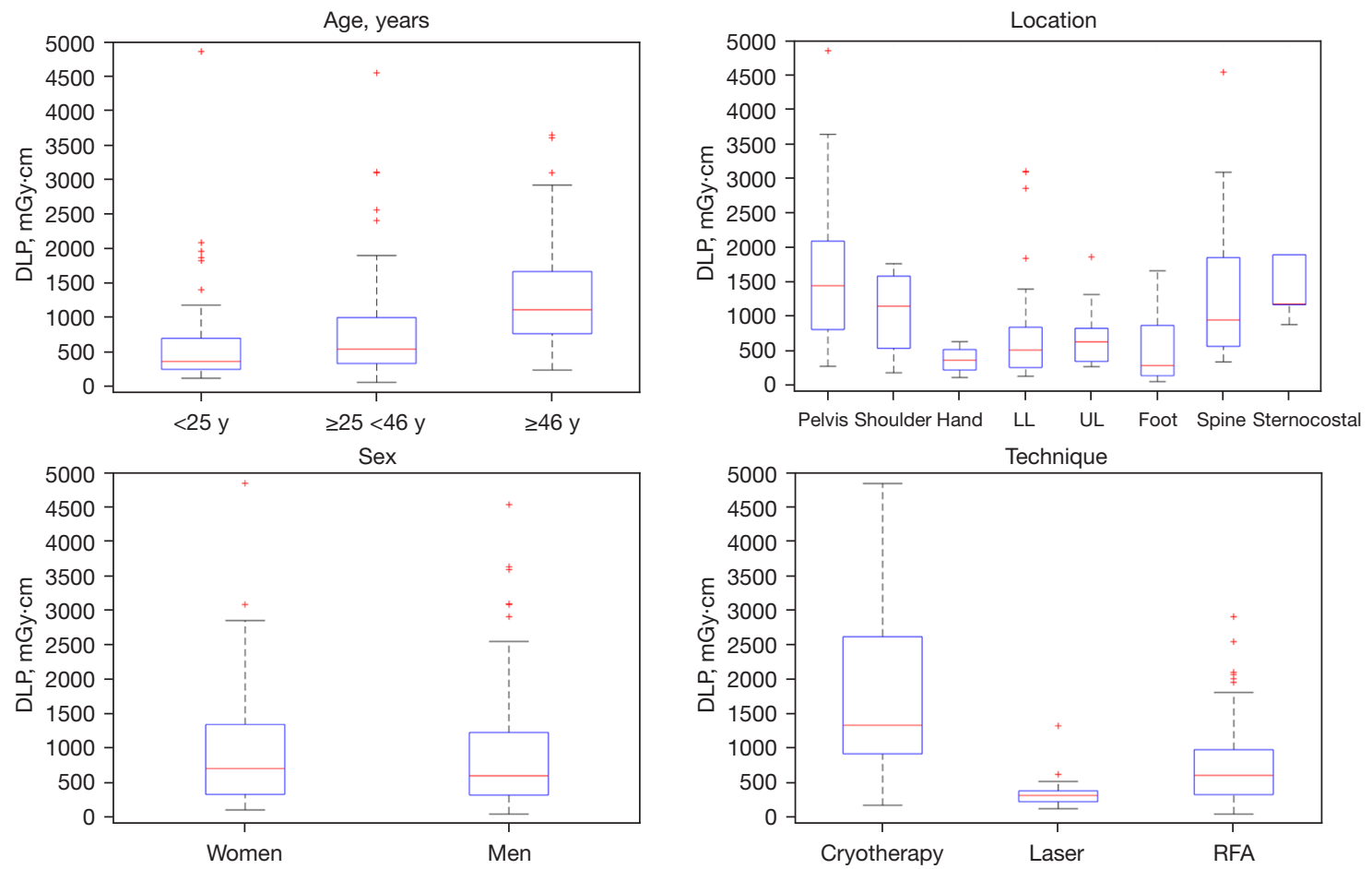

Figure 2 Boxplot of total dose length product as function of patient's age, sex, anatomical location or technique used for bone lesions percutaneous destructions. DLP, dose length product; y, years; LL, lower limb (except foot); UL, upper limb (except hand); RFA, radiofrequency ablation.
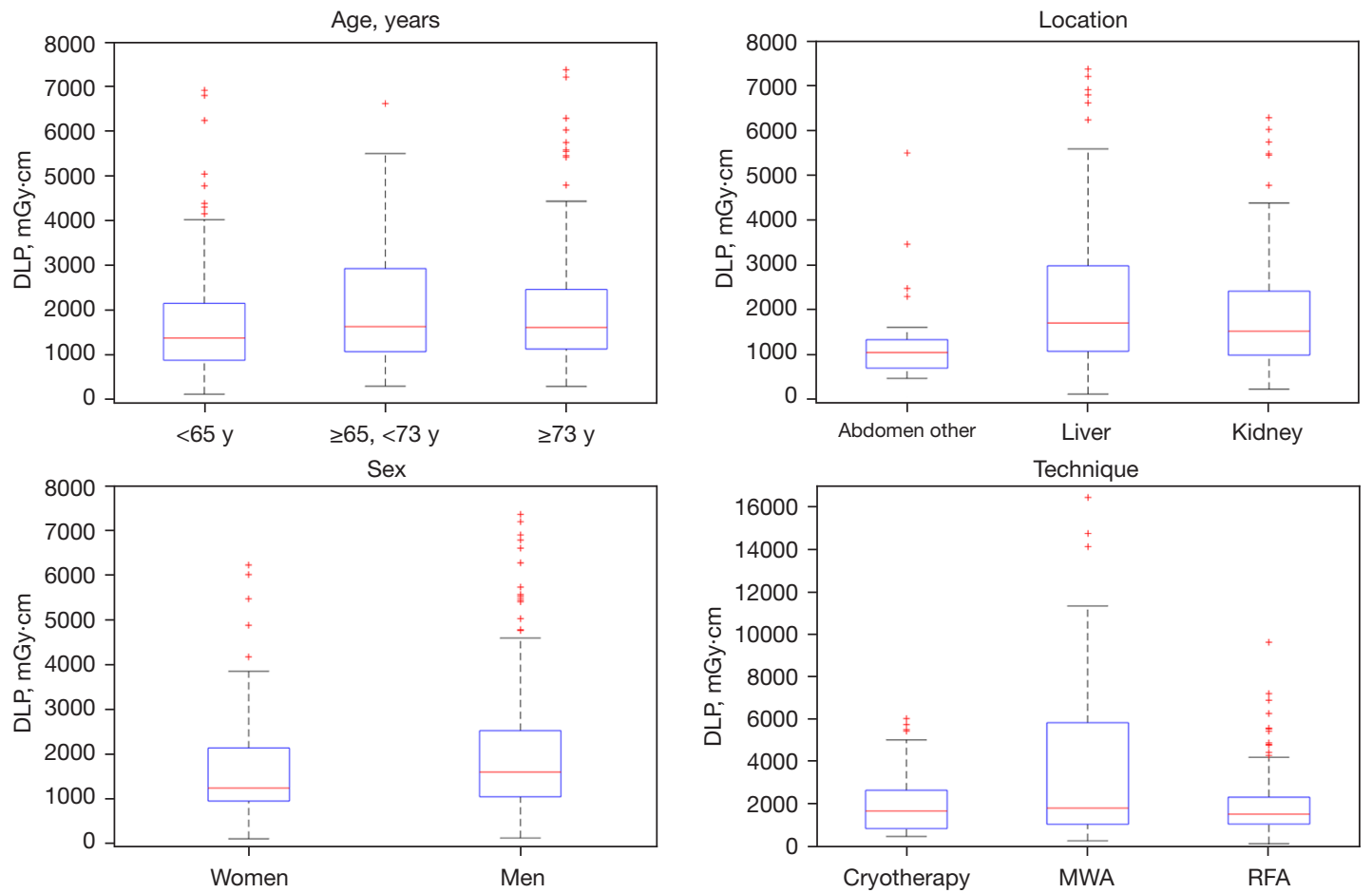

Figure 3 Boxplot of total dose length product as function of patient's age, sex, anatomical location or technique used for percutaneous destructions of abdominal lesions. DLP, dose length product; y, years; MWA, microwave ablation; RFA, radiofrequency ablation. 

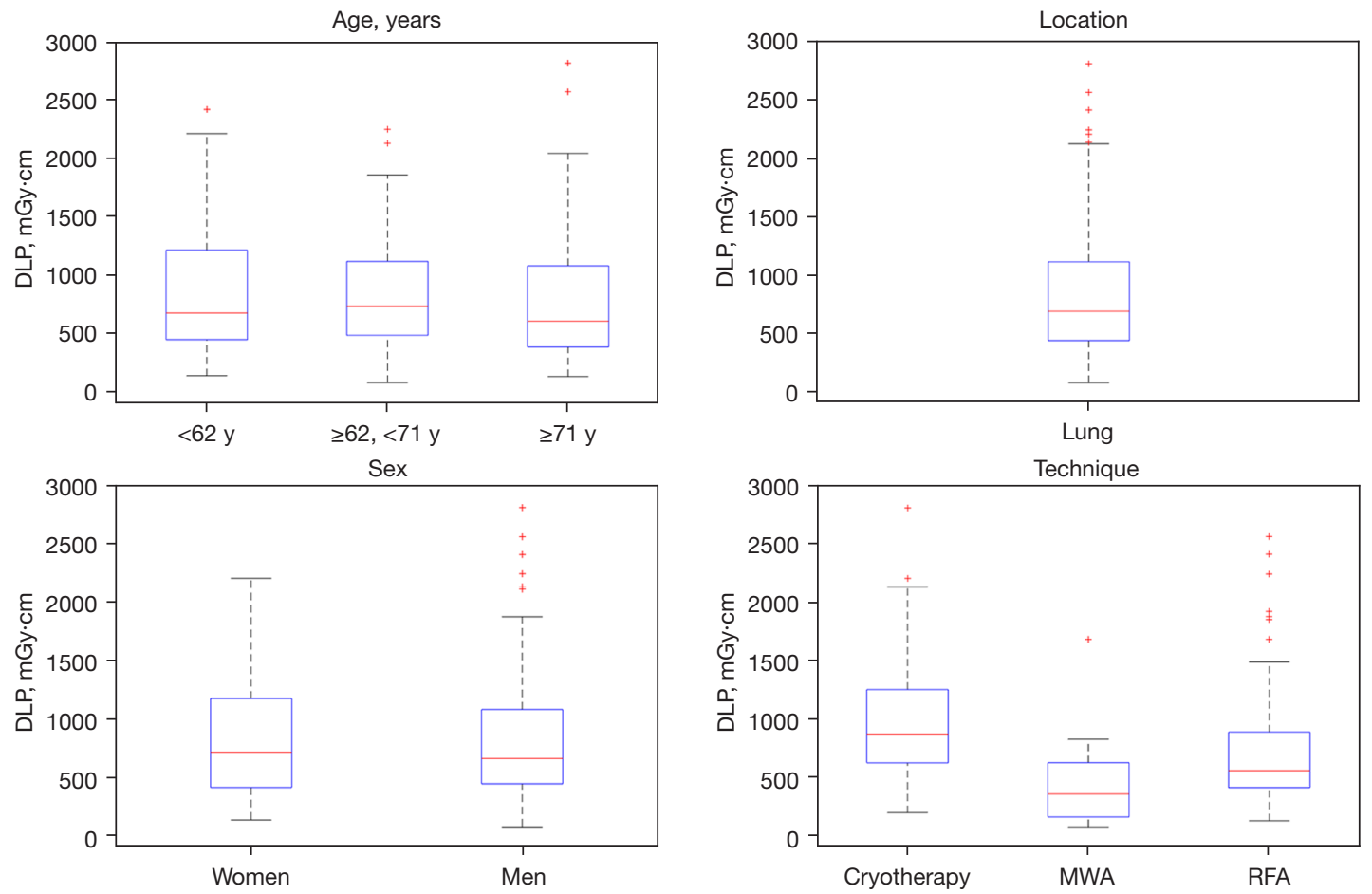

Figure 4 Boxplot of total dose length product as function of patient's age, sex, anatomical location or technique used for percutaneous destructions of thoracic lesions. DLP, dose length product; y, years; MWA, microwave ablation; RFA, radiofrequency ablation.

helical acquisitions is presented for percutaneous destructions of bone, abdominal and thoracic lesions in Tables 2-4.

\section{Percutaneous destruction of bone lesions}

The doses were not significantly different between men and women and according to the technique (Table 2). A statistical difference was found for doses according to the patient's age [526.4 (95\% CI: 333.4-831.2) $\mathrm{mGy} \cdot \mathrm{cm}$ for patients $<25$ years old to 794.9 ( $95 \%$ CI: $502.7-1,256.9) \mathrm{mGy} \cdot \mathrm{cm}$ for patients $\geq 46$ years old; $\mathrm{P}=0.0082]$ and location of the lesion [253.8 (95\% CI: 155.4-414.3) $\mathrm{mGy} \cdot \mathrm{cm}$ for feet to $1,015.4$ (95\% CI: 620.5-1,661.6) $\mathrm{mGy} \cdot \mathrm{cm}$ for spine, $\mathrm{P}<0.0001]$.

\section{Percutaneous destruction of abdominal tumors}

No significant differences of the doses were found according to the patient's age, the tumor location or the technique (Table 3). The patient's gender was found a significant parameter $(\mathrm{P}<0.0001)$, with doses lower for women $[1,309.3$ (95\% CI: $1,019.5-1,681.5) \mathrm{mGy} \cdot \mathrm{cm}]$ than for men $[1,598.7$ (95\% CI: 1,254.3-2,037.6) mGy.cm].

\section{Percutaneous destruction of thoracic tumors}

None of the variables included in multivariate analysis, age, gender and technique, was found significant (Table 4).

\section{Discussion}

This study showed that the dose delivered to the patient depended of the patient's age and the lesion location for the destruction of bone lesions, and of the gender for abdominal lesions. The technique used had no impact on the dose after adjustment whatever the organ involved.

This study is, to our knowledge, the first national multicenter study to investigate on 822 patients the impact of patient's age, gender, and lesion location in the percutaneous destruction of bone, thoracic and abdominal lesions, performed using the three major techniques. Only few monocentric studies have evaluated factors that may impact the dose delivered during abdominal percutaneous destructions. McCathy et al. showed in 245 patients an increase of the dose delivered during percutaneous hepatic ablation under CT guidance by RFA, MWA and electroporation, correlated with weight, intravenous injection of contrast product, hydrodissection during the procedure and multiple lesions (11). Two other monocentric single-organ and single-technique studies evaluated the 
Table 2 Percutaneous destruction of bone lesions

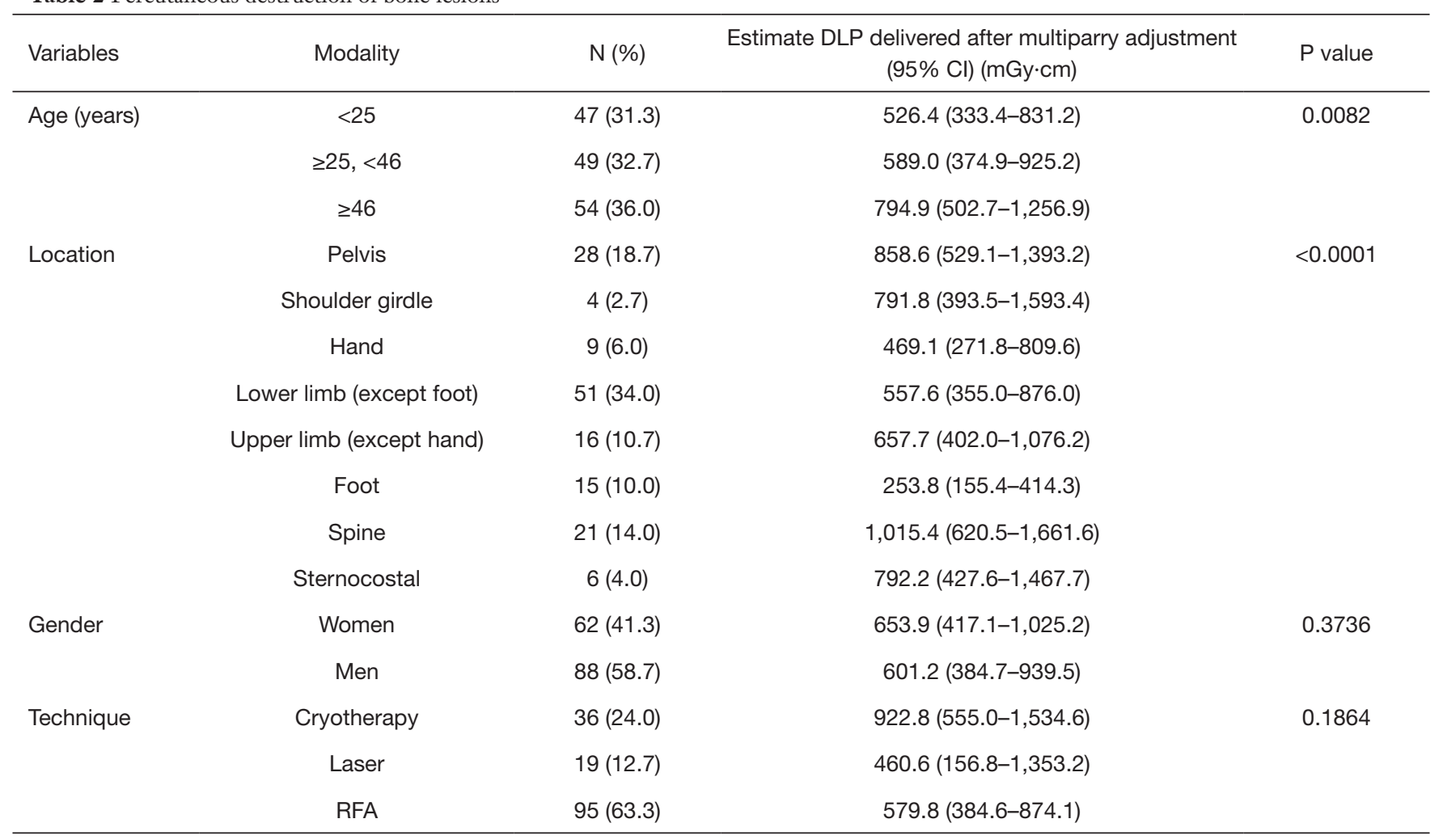

DLP, dose length product; $\mathrm{Cl}$, confidence interval; RFA, radiofrequency ablation.

Table 3 Percutaneous destruction of abdominal tumors

\begin{tabular}{lccc}
\hline Variables & Modality & $\mathrm{N}(\%)$ & $\begin{array}{c}\text { Estimate DLP delivered after multiparry adjustment } \\
(95 \% \mathrm{Cl})(\mathrm{mGy} \cdot \mathrm{cm})\end{array}$ \\
\hline Age (years) & $<65$ & $152(32.8)$ & $1,354.2(1,055.8-1,736.9)$ \\
& $\geq 65,<73$ & $144(31.1)$ & $1,489.7(1,160.5-1,912.3)$ \\
& 273 & $167(36.1)$ & $1,501.0(1,170.8-1,924.4)$ \\
Location & Liver & $233(50.3)$ & $1,490.6(1,162.4-1,911.5)$ \\
& Kidney & $205(44.3)$ & $1,452.0(1,137.8-1,852.9)$ \\
Gender & $25(5.4)$ & $1,399.1(993.2-1,970.9)$ \\
Other abdominal locations & $120(25.9)$ & $1,309.3(1,019.5-1,681.5)$ \\
Technique & Women & $343(74.1)$ & $1,598.7(1,254.3-2,037.6)$ \\
& Men & $71(15.3)$ & $1,404.7(1,067.0-1,849.3)$ \\
& Cryotherapy & $68(14.7)$ & $1,423.6(1,073.4-1,888.2)$
\end{tabular}

DLP, dose length product; $\mathrm{Cl}$, confidence interval; MWA, microwave ablation; RFA, radiofrequency ablation. 
Table 4 Percutaneous destruction of thoracic tumors

\begin{tabular}{|c|c|c|c|c|}
\hline Variables & Modality & $\mathrm{N}(\%)$ & $\begin{array}{l}\text { Estimate DLP delivered after multiparry adjustment } \\
\qquad(95 \% \mathrm{Cl})(\mathrm{mGy} \cdot \mathrm{cm})\end{array}$ & $P$ value \\
\hline \multirow[t]{3}{*}{ Age } & $<62$ & $62(29.7)$ & 619.5 (448.7-855.5) & 0.8273 \\
\hline & $\geq 62,<71$ & $72(34.4)$ & $642.3(465.5-886.2)$ & \\
\hline & $\geq 71$ & 75 (35.9) & $612.4(444.6-843.5)$ & \\
\hline Gender & Men & $125(59.8)$ & $658.0(479.0-903.7)$ & \\
\hline \multirow[t]{2}{*}{ Technique } & Cryotherapy & $40(19.1)$ & $767.9(541.0-1,090.1)$ & 0.1418 \\
\hline & MWA & $9(4.3)$ & $482.5(305.2-762.7)$ & \\
\hline
\end{tabular}

DLP, dose length product; $\mathrm{Cl}$, confidence interval; MWA, microwave ablation; RFA, radiofrequency ablation.

technical parameters correlated to the dose in cryotherapy percutaneous destruction in 97 patients with kidney lesions (12) and in 18 patients with liver lesions (13) but patient characteristics (age, gender, weight, etc.) were not taken into account.

We found that the dose delivered was significantly different according to the patient's gender for abdominal lesions, but not for bone and thoracic lesions. The morphotype at the abdominal level may be the reason; indeed, men show a larger corpulence than women and a different androgenic fat distribution, requiring a $\mathrm{X}$-ray beam hardening by increasing $\mathrm{kVp}$ and $\mathrm{mAs}$ (14-16). The bones and the thorax, although in general discretely thicker in terms of diameter in men, are finally of fairly close tissue composition between men and women and do not present any notable difference in distribution unlike the abdomen. Moreover, the presence of the breasts on the thorax could compensate for the discretely higher thoracic thickness of the rest of the thorax in men. This could explain why there is no difference, the gestures being technically similar.

Patient's age was found significantly correlated to the dose for bone lesions, but not for abdominal and thoracic lesions. Regarding bone location, the result is significant but the age ranges with a first tiercile up to 25 years and a third tiercile from 46 years attest of a probable confounding factor consisting in the type of tumor treated. Indeed, bone tumors treated by percutaneous destruction in young people are mainly osteoid osteomas, whereas in older people these are more frequently metastases $(17,18)$. Considering that fact, one may be aware that osteoid osteomas may require lower CT scan controls: only one needle placement might be effective because of their infra-centimetric size.

About the lesion location, it only impacted the dose received for bone lesions. The dose is indeed strongly associated with the patient thickness and attenuation as function of the anatomical location. The doses received for the feet and hands are 2 to 3 times lower than for the spine or pelvic girdle. Also, procedures with deeper pathways are often more complex and may thus require more iterative controls generating a higher dose delivered to the patient. For the abdominal location, the majority of procedures concerned the liver and kidneys. The patient thickness and attenuation in these regions are quite close and therefore the acquisition parameters used are quite similar. This could explain the absence of difference observed on the abdominal localizations.

Last, regarding the technique used, it had no impact on the dose delivered after analysis weighted with age, sex, location and number of helical acquisitions. For MWA and RFA, our results are consistent with a previous study in percutaneous liver ablations (11). Our recovered doses for these two techniques remain quite close to those found in other studies $(11,19,20)$. Regarding cryoablation, it seems to deliver higher doses than the other techniques. Two studies of the dose received during percutaneous CT-guided liver tumor ablation procedures showed almost twice or up to 3 times higher dose delivered with cryoablation compared to RFA procedures $(13,19)$. This was explained in two studies by a generally higher number of needles required in cryoablation procedures than in RFA or MW as to generate sufficient ice balls and because of the repetitive checks of the ice ball sizes $(12,21)$. Our results in univariate analysis are consistent with these data, but our study showed no impact 
of the technique on the dose after weighting for age, sex, location and number of helical acquisitions. This may be due to the fact that the doses in our study are much lower than those published for cryoablation in the literature, about 2 to 8 times lower. The mean DLP was $1295 \mathrm{mGy} \cdot \mathrm{cm}$ in our study, lower than other DLPs previously published in studies with a limited number of patients (42 to 50 patients versus 147 in our study) $(12,13,19)$. Our results could be explained by the optimization of the practices and the use of more recent scanners thus less irradiating compared to the previous studies conducted between 2011 and 2015 . Studies have already shown that protocols can greatly reduce the radiation doses by decreasing the tube current and kilovoltage, reducing the number of monitoring scans or using CT fluoroscopy during the targeting phase to limit the number of helical CT scans acquired $(12,21)$.

Our study has some limitations. The main limitation, also reported in other previously published studies $(22,23)$, was that the body mass index (BMI) was not collected. Indeed, as weight and height impact the DLP in interventional radiology (15), systematic record of BMI would be interesting to add in future studies. It would also have been interesting to collect more detailed data on tumor type (metastasis or primary tumor) and size, which may impact on the length of procedure and the dose administered. It would also have been interesting to know the number of needles used during the procedures. Finally, ablation techniques are not homogenous among all participating centers, which may have induced bias in the study. A maximum number of patients per center was defined in order to avoid a particular center having too much weight in the sample and we made an adjustment to the inclusion center but it was not feasible for the percutaneous bone destruction analysis as the number of patients per center was too low.

\section{Conclusions}

Our study showed that the dose delivered to the patient during percutaneous destructions depended on age and lesion location for bone lesions, and on gender for abdominal lesions. The technique used was not found significant in multivariate analysis, for all organs involved. Further studies would be needed to propose sharper reference dose levels.

\section{Acknowledgments}

The authors are very grateful to the staff of the 49 imaging departments (medical physicists and/or radiologists) who took the time and trouble to collect and check the data.

Funding: None.

\section{Footnote}

Reporting Checklist: The authors have completed the STROBE reporting checklist. Available at https://dx.doi. org/10.21037/qims-21-744

Conflicts of Interest: All authors have completed the ICMJE uniform disclosure form (available at https://dx.doi. org/10.21037/qims-21-744). The authors have no conflicts of interest to declare.

Ethical Statement: The authors are accountable for all aspects of the work in ensuring that questions related to the accuracy or integrity of any part of the work are appropriately investigated and resolved. The study was conducted in accordance with the Declaration of Helsinki (as revised in 2013). The study was approved by the Institutional Review Board of Nîmes University Hospital (No. 19.01.03) and informed consent for this retrospective analysis was waived.

Open Access Statement: This is an Open Access article distributed in accordance with the Creative Commons Attribution-NonCommercial-NoDerivs 4.0 International License (CC BY-NC-ND 4.0), which permits the noncommercial replication and distribution of the article with the strict proviso that no changes or edits are made and the original work is properly cited (including links to both the formal publication through the relevant DOI and the license). See: https://creativecommons.org/licenses/by-nc-nd/4.0/.

\section{References}

1. Helmberger $T$. The evolution of interventional oncology in the 21st century. Br J Radiol 2020;93:20200112.

2. Escudier B, Porta C, Schmidinger M, Rioux-Leclercq N, Bex A, Khoo V, Grünwald V, Gillessen S, Horwich A; ESMO Guidelines Committee. Electronic address: clinicalguidelines@esmo.org. Renal cell carcinoma: ESMO Clinical Practice Guidelines for diagnosis, treatment and follow-upt. Ann Oncol 2019;30:706-20.

3. de Baère T, Aupérin A, Deschamps F, Chevallier P, Gaubert Y, Boige V, Fonck M, Escudier B, Palussiére J. Radiofrequency ablation is a valid treatment option for 
lung metastases: experience in 566 patients with 1037 metastases. Ann Oncol 2015;26:987-91.

4. Vogel A, Cervantes A, Chau I, Daniele B, Llovet JM, Meyer T, Nault JC, Neumann U, Ricke J, Sangro B, Schirmacher P, Verslype C, Zech CJ, Arnold D, Martinelli E; ESMO Guidelines Committee. Hepatocellular carcinoma: ESMO Clinical Practice Guidelines for diagnosis, treatment and follow-up. Ann Oncol 2018;29:iv238-55.

5. Van Cutsem E, Cervantes A, Adam R, Sobrero A, Van Krieken JH, Aderka D, et al. ESMO consensus guidelines for the management of patients with metastatic colorectal cancer. Ann Oncol 2016;27:1386-422.

6. Montgomery ML, Sullivan JP. Advances in interventional radiology. The search for less invasive management sparks new approaches. Postgrad Med 2001;109:93-4, 97-9, 103-4.

7. Greffier J, Ferretti G, Rousseau J, Andreani O, Alonso E, Rauch A, et al. National dose reference levels in computed tomography-guided interventional procedures-a proposal. Eur Radiol 2020;30:5690-701.

8. Foerth M, Seidenbusch MC, Sadeghi-Azandaryani M, Lechel U, Treitl KM, Treitl M. Typical exposure parameters, organ doses and effective doses for endovascular aortic aneurysm repair: Comparison of Monte Carlo simulations and direct measurements with an anthropomorphic phantom. Eur Radiol 2015;25:2617-26.

9. Alagic Z, Alagic H, Bujila R, Srivastava S, Jasim S, Lindqvist M, Wick MC. First experiences of a lowdose protocol for CT-guided musculoskeletal biopsies combining different radiation dose reduction techniques. Acta Radiol 2020;61:28-36.

10. Brenner DJ, Hall EJ. Computed tomography--an increasing source of radiation exposure. N Engl J Med 2007;357:2277-84.

11. McCarthy CJ, Kilcoyne A, Li X, Cahalane AM, Liu B, Arellano RS, Uppot RN, Gee MS. Radiation Dose and Risk Estimates of CT-Guided Percutaneous Liver Ablations and Factors Associated with Dose Reduction. Cardiovasc Intervent Radiol 2018;41:1935-42.

12. Levesque VM, Shyn PB, Tuncali K, Tatli S, Nawfel RD, Olubiyi O, Silverman SG. Radiation dose during CTguided percutaneous cryoablation of renal tumors: Effect of a dose reduction protocol. Eur J Radiol 2015;84:2218-21.

13. Park BK, Morrison PR, Tatli S, Govindarajulu U, Tuncali K, Judy P, Shyn PB, Silverman SG. Estimated effective dose of CT-guided percutaneous cryoablation of liver tumors. Eur J Radiol 2012;81:1702-6.

14. Vañó E, Miller DL, Martin CJ, Rehani MM, Kang K, Rosenstein M, Ortiz-López P, Mattsson S, Padovani R,
Rogers A; Authors on behalf of ICRP. ICRP Publication 135: Diagnostic Reference Levels in Medical Imaging. Ann ICRP 2017;46:1-144.

15. Miller DL, Kwon D, Bonavia GH. Reference levels for patient radiation doses in interventional radiology: proposed initial values for U.S. practice. Radiology 2009;253:753-64.

16. Finucane MM, Stevens GA, Cowan MJ, Danaei G, Lin JK, Paciorek CJ, Singh GM, Gutierrez HR, Lu Y, Bahalim AN, Farzadfar F, Riley LM, Ezzati M; Global Burden of Metabolic Risk Factors of Chronic Diseases Collaborating Group (Body Mass Index). National, regional, and global trends in body-mass index since 1980: systematic analysis of health examination surveys and epidemiological studies with 960 country-years and 9.1 million participants. Lancet 2011;377:557-67.

17. Rosenthal D, Callstrom MR. Critical review and state of the art in interventional oncology: benign and metastatic disease involving bone. Radiology 2012;262:765-80.

18. Filippiadis DK, Tutton S, Kelekis A. Percutaneous bone lesion ablation. Radiol Med 2014;119:462-9.

19. Leng S, Christner JA, Carlson SK, Jacobsen M, Vrieze TJ, Atwell TD, McCollough CH. Radiation dose levels for interventional CT procedures. AJR Am J Roentgenol 2011;197:W97-103.

20. Tsalafoutas IA, Tsapaki V, Triantopoulou C, Gorantonaki A, Papailiou J. CT-guided interventional procedures without CT fluoroscopy assistance: patient effective dose and absorbed dose considerations. AJR Am J Roentgenol 2007;188:1479-84.

21. Zhong J, Gallagher M, Hounslow C, Iball G, Wah T. Radiation dose reduction in CT-guided cryoablation of renal tumors. Diagn Interv Radiol 2021;27:244-8.

22. Greffier J, Etard C, Mares O, Pereira F, Defez D, Duverger C, Branchereau P, Beregi JP, Coulomb R, Larbi A. Patient dose reference levels in surgery: a multicenter study. Eur Radiol 2019;29:674-81.

23. Etard C, Bigand E, Salvat C, Vidal V, Beregi JP, Hornbeck A, Greffier J. Patient dose in interventional radiology: a multicentre study of the most frequent procedures in France. Eur Radiol 2017;27:4281-90.

Cite this article as: Rojo M, Hamard A, Serrand C, de Forges H, Beregi JP, Greffier J, Frandon J. A national dose analysis of guided tumor destruction: influence of sex, age, localization and destruction technique used. Quant Imaging Med Surg 2022;12(3):1968-1976. doi: 10.21037/qims-21-744 
Supplementary

Table S1 Dose length product values according to the number of lesions treated

\begin{tabular}{lccc}
\hline Percutaneous destruction of & Number of lesions treated & N & DLP (mGy.cm) \\
\hline Bone lesions & 1 & 143 & $973 \pm 982(52-6,142)$ \\
& 2 & 5 & $1,021 \pm 777(356-2,244)$ \\
Abdominal tumours & 3 & 2 & $2,257 \pm 416(1,963-2,551)$ \\
& 1 & 386 & $2,028 \pm 1,915(112-16,455)$ \\
Pulmonary tumours & 2 & 60 & $2,645 \pm 2,619(409-14,145)$ \\
& 3 & 14 & $2,753 \pm 2,720(821-10,476)$ \\
All tumours & 4 & 1 & 1,098 \\
& 5 & 1 & 1,484 \\
& 6 & 1 & $1,976.4$ \\
& 1 & 170 & $775 \pm 493(75-2,810)$ \\
& 2 & 26 & $1,062 \pm 609(148-2,564)$ \\
& 3 & 10 & $1,013 \pm 835(295-3,157)$ \\
& 4 & 3 & $1,009 \pm 1,215(237-2,410)$ \\
& 1 & 699 & $1,509 \pm 1,619(52-16,455)$ \\
& 2 & 91 & $2,103 \pm 2,280(148-14,145)$ \\
& 3 & 26 & 1,976 \\
\hline & 4 & 4 & $1,032 \pm 993(237-2,410)$ \\
& 5 & 1 & 1,484 \\
& 6 & & $1946 \pm 2,194(295-10,476)$ \\
\end{tabular}

